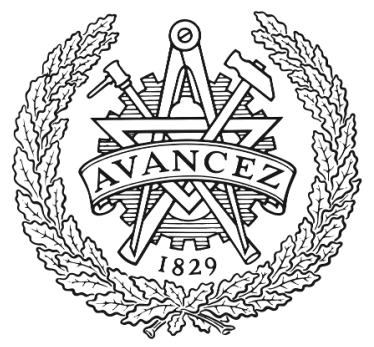

CHALMERS

UNIVERSITY OF TECHNOLOGY

\title{
Allylic and Allenylic Dearomatization of Indoles promoted by Graphene Oxide via Covalent Grafting Activation Mode
}

Downloaded from: https://research.chalmers.se, 2023-04-26 14:06 UTC

Citation for the original published paper (version of record):

Bellini, D., Bottoni, A., Calvaresi, M. et al (2020). Allylic and Allenylic Dearomatization of Indoles promoted by Graphene Oxide via Covalent Grafting Activation Mode. Chemistry - A European Journal, 26(46): 10427-10432.

http://dx.doi.org/10.1002/chem.202001373

N.B. When citing this work, cite the original published paper. 
This is the peer reviewed version of the following article:

Lorenzo Lombardi, Daniele Bellini, Andrea Bottoni, Matteo Calvaresi, Magda Monari, Alessandro Kovtun, Vincenzo Palermo, Manuela Melucci and Marco Bandini, Allylic and Allenylic Dearomatization of Indoles promoted by Graphene Oxide via Covalent Grafting Activation Mode

which has been published in final form at: https://doi.org/10.1002/chem.202001373

This article may be used for non-commercial purposes in accordance with Wiley Terms and Conditions for Use of Self-Archived Versions.

(C) 2017 Wiley-VCH Verlag GmbH \& Co. KGaA, Weinheim 


\title{
Allylic and Allenylic Dearomatization of Indoles promoted by Graphene Oxide via Covalent Grafting Activation Mode
}

\author{
Lorenzo Lombardi, ${ }^{[a]}$ Daniele Bellini, ${ }^{[a]}$ Andrea Bottoni, ${ }^{[a]}$ Matteo Calvaresi, ${ }^{[a]}$ Magda Monari, ${ }^{[a]}$ \\ Alessandro Kovtun, ${ }^{[c]}$ Vincenzo Palermo ${ }^{[c, d]}$ Manuela Melucci ${ }^{[c]}$ and Marco Bandini ${ }^{[a, b]}$
}

\begin{abstract}
The site-selective allylative and allenylative dearomatization of indoles with alcohols is performed under carbocatalytic regime in the presence of graphene oxide (GO, $10 \mathrm{wt} \%$ loading) as the promoter. Metal-free conditions, absence of stoichiometric additive, environmentally friendly conditions $\left(\mathrm{H}_{2} \mathrm{O} / \mathrm{CH}_{3} \mathrm{CN}, 55^{\circ} \mathrm{C}, 6 \mathrm{~h}\right.$ ), broad substrate scope (33 examples, yield up to $92 \%$ ) and excellent site- and stereoselectivity characterize the present methodology. Moreover, a covalent activation model exerted by GO functionalities was corroborated by spectroscopic, experimental and computational evidences. Recovering and regeneration of the $\mathrm{GO}$ catalyst via simple acidic treatment was also documented.
\end{abstract}

The dearomatization reaction of indoles is receiving growing attention in the synthetic organic chemistry scenario, providing rapid access to complex 3D molecular architectures starting from widely available aromatic $2 \mathrm{D}$-platforms. ${ }^{[1]}$ In this context, the combination of catalytic tools and environmentally benign substrates is an ultimate goal in order to conjugate the intrinsic synthetic utility of dearomative protocols with crucial requirements of nowadays organic synthetic chemistry such as sustainability.

Undoubtfully, $\pi$-alcohols represent a convenient portfolio of substrates for arene manipulations featuring the enviable advantage of producing water as the only stoichiometric sideproduct. ${ }^{[2]}$ However, their employment has proven challenging due to the intrinsic inertness towards nucleophilic substitutiontype reactions that makes mandatory the use of harsh reaction conditions or stoichiometric co-additives.

In this segment, pioneering works on the use of allylic alcohols deal with the combination of transition metal-based catalysts and acid or base additives. In particular, Tamaru $\left([\mathrm{Pd}(0)] / \mathrm{BEt}_{3}\right),{ }^{[3 \mathrm{a}]}$ Trost $\left([\mathrm{Pd}(0)] / 9-\mathrm{BBN}-\mathrm{C}_{6} \mathrm{H}_{13}\right),{ }^{[3 \mathrm{~b}]}$ You $([\mathrm{Ru}(\mathrm{II})] / \mathrm{pTsOH}),{ }^{[3 \mathrm{c}]}$ You $\left([\operatorname{lr}(\mathrm{I})] / \mathrm{Fe}(\mathrm{OTf})_{2}\right)^{[3 \mathrm{~d}]}$ and Bisai $\left(\left[\mathrm{Pd}(0) / \mathrm{BEt}_{3} / \mathrm{KOtBu}\right]\right)^{[3 \mathrm{e}]}$ documented

[a] L. Lombardi, D. Bellini, Prof. A. Bottoni, Prof. M. Calvaresi, Prof. M. Monari, Prof. M. Bandin

Dipartimento di Chimica "Giacomo Ciamician"

Alma Mater Studiorum - Università di Bologna

via Selmi 2, 40126 Bologna, Italy

E-mail: marco.bandini@unibo.it

[b] Prof. M. Bandini

Consorzio C.I.N.M.P.I.S.

via Selmi 2, 40126 Bologna, Italy

[c] Dr. M. Melucci, Dr. A. Kovtun, Dr. V. Palermo

Istituto per la Sintesi Organica e Fotoreattività (ISOF) - CNR via Gobetti 101, 40129 Bologna

[d] Chalmers University of Technology, Industrial and Materials Science, Hörsalsvägen 7A, SE-412 96 Goteborg, Sweden

Supporting information for this article is given via a link at the end of the document. very elegant methodologies (Figure 1). Additionally, Pd-mediated allylic $\mathrm{C}-\mathrm{H}$ activations ${ }^{[4 \mathrm{a}]}$ and site-selective insertion into $\mathrm{C}-\mathrm{C}$ triple bonds ${ }^{[4 b]}$ deserve particular mention as parallel methodologies in the indole allylative dearomatization realm.

Despite efficiency, these protocols suffer of some undoubted limitations related to the need of noble-metal complexes, stoichiometric acid or base additives and rigorous anhydrous conditions. Consequently, the search for more economic and environmentally benign 2D $\rightarrow 3 \mathrm{D}$ chemical space mutations of indoles with alcohols is ongoing.

Tamaru, Trost, You, Bisai - allylic alcohols

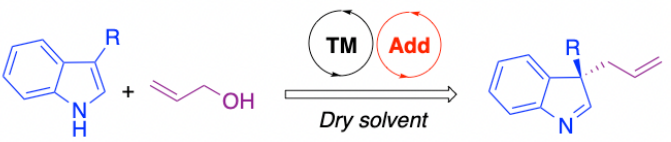

TM transition metal catalysis Add Stoichiometric additives 1. $[\mathrm{Pd}(0)],[\mathrm{Ru}(\mathrm{II})],[\mathrm{Ir}(\mathrm{I})]$ Add $\mathrm{BR}_{3}, \mathrm{Fe}(\mathrm{OTf})_{2}, \mathrm{KO}$ tBu

this work

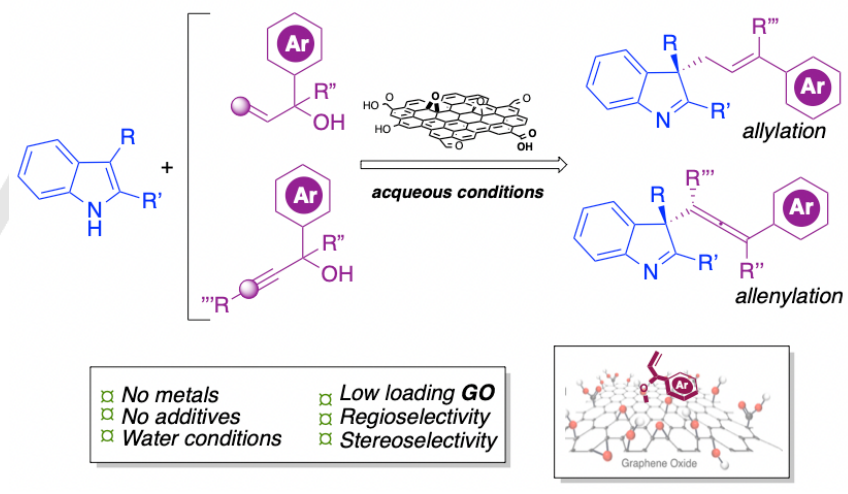

Figure 1. State of the art (metal-catalyzed allylative dearomatization of indoles with alcohols) and schematic representation of the present GO-assisted metal-free dearomatization of indoles with allylic/propargylic alcohols.

In this regard, we envisioned that the emerging field of carbocatalysis could provide a concrete hint to address these challenges ${ }^{[6]}$ As a matter of fact, the Brønsted acidity provided by some nanostructured functionalized carbon-based materials could assist the selective alcohol activation and the network of functional groups, together with the non-innocent $\pi$-matrix of the carbon material, could synergistically contribute in fine-tuning the arene reactivity.

In this context, graphene oxide $(\mathrm{GO})^{[7]}$ is collecting growing credit in the area of organic transformations being effectively 
employed either as a catalyst or promoter (i.e. co-reagent) ${ }^{[8]}$ in numerous $\mathrm{C}-\mathrm{C}$ and $\mathrm{C}-\mathrm{X}$ bond forming transformations. ${ }^{[9]}$

In this article, our preliminary findings in the GO-assisted dearomatization of indoles with allylic alcohols as well as the covalent activation mode exerted by the GO-surface will be presented and supported by experimental, computational and spectroscopic evidences (Figure 1 lower).

In light of our ongoing interest in catalytic dearomatization reactions, ${ }^{[10]}$ we selected $N(\mathrm{H})-2,3-\mathrm{Me}_{2}$-indole (1a) and the secondary allylic alcohol $2 a$ as model substrates for the optimization of the reaction conditions. Upon an extensive survey of reaction conditions the use of $10 \mathrm{wt} \%$ loading of GO enabled the selective formation of the desired C(3)-allylated dearomatized compound 3 aa in $70 \%$ yield under very mild conditions $\left(\mathrm{CH}_{3} \mathrm{CN}: \mathrm{H}_{2} \mathrm{O} 4: 1,55^{\circ} \mathrm{C}, 6 \mathrm{~h}\right.$, entry 1 , Table 1$) .{ }^{[11]}$

Table 1. Variations from the optimal conditions in the allylic dearomatization of indoles.

$\frac{\operatorname{Run}^{[\mathrm{a}]} \quad \text { Deviations from optimal }}{\begin{array}{c}\text { Yield (\%) } \\ \mathbf{3 a a}^{[\mathrm{b}]}\end{array}}$

\begin{tabular}{|c|c|c|}
\hline 1 & -- & 70 \\
\hline 2 & No GO, $36 \mathrm{~h}$ & 12 \\
\hline 3 & 5 wt $\%$ of $\mathrm{GO}$ & 59 \\
\hline 4 & $25 w t \%$ of $G O$ & 69 \\
\hline $5^{[\mathrm{cc}]}$ & Pre-sonication of GO & 67 \\
\hline 6 & with GOr (25 wt\%) & 12 \\
\hline 7 & Dioxane instead of $\mathrm{CH}_{3} \mathrm{CN}, 25 \mathrm{wt} \%$ of $\mathrm{GO}$ & 66 \\
\hline 8 & THF instead of $\mathrm{CH}_{3} \mathrm{CN}, 25 \mathrm{wt} \%$ of $\mathrm{GO}$ & 30 \\
\hline 9 & $\mathrm{CH}_{3} \mathrm{CN}$ as the solvent, $24 \mathrm{~h}$ & 25 \\
\hline 10 & $\mathrm{H}_{2} \mathrm{O}$ as the solvent, $25 \mathrm{wt} \%$ of $\mathrm{GO}$ & 62 \\
\hline 11 & $\mathrm{H}_{2} \mathrm{O}$ as the solvent, $25 \mathrm{wt} \%$ of $\mathrm{GO}, \mathrm{rt}, 16 \mathrm{~h}$ & 47 \\
\hline 12 & $\mathrm{H}_{2} \mathrm{O}$ as the solvent, $25 \mathrm{wt} \%$ of $\mathrm{GO}, 80^{\circ} \mathrm{C}$ & 62 \\
\hline 13 & $\mathrm{AcOH} \mathrm{pH}=4$ & 44 \\
\hline $14^{[\mathrm{d}]}$ & $\mathrm{Mn}(\mathrm{OAc})_{2} \cdot 4 \mathrm{H}_{2} \mathrm{O}$ and no $\mathrm{GO}$ & traces \\
\hline $15^{[\mathrm{e}]}$ & EDTA as an additive & 68 \\
\hline 16 & Under $\mathrm{N}_{2}$ and degassed solvents & 69 \\
\hline $17^{[\mathrm{f}]}$ & Gram scale $(5 \mathrm{mmol}$ of $1 \mathrm{a})$ & 78 \\
\hline
\end{tabular}

[a] All the reactions were carried out with reagent grade solvents, unless otherwise specified $(\mathbf{1} \mathbf{a} / \mathbf{2} \mathbf{a}=1 / 2$ on $0.15 \mathrm{mmol}$ of $\mathbf{1 a}, 0.1 \mathrm{M})$. [b] Determined after flash chromatography. [c] Sonication for $2 \mathrm{~min}$, in probe sinicator. [d] [Mn]: $1.8 \mathrm{~mol} \%$. [e] EDTA: $200 \mu \mathrm{L}$ of $43 \mathrm{mM}$ water solution. [f] GO (10 wt\%) 3aa: $1.13 \mathrm{gr}(16 \mathrm{~h})$.

Remarkably, while the potentially competitive $N(1)$ - and $\mathrm{C}(5)$-allylation products were observed only sporadically (traces), the indolenine $(E)$-3aa was recorded almost exclusively in a stereospecific manner ( $\mathrm{S}_{\mathrm{N}} 2$ '-like pathway). $\alpha$

The background reaction was incomparable in terms of product realization ( $12 \%$ yield, $36 \mathrm{~h}$, entry 2 ) with respect to the optimal GO-based protocol $(70 \%$, entry 1$)$. Additionally, the oxygenated groups of the GO surface proved essential for the condensation (vide infra), indeed reduced $\mathrm{GO}$ analogous proved inert as a promoter (yield $=12 \%$, entry 6 ).

The high Go-loading is one of the critical aspects usually encountered in GO-based carbo-catalyzed organic transformations. Loadings commonly fluctuate around 100-200 wt $\%$ posing serious issues in term of process scalability. In this methodology, we were pleased to verify that $10 \mathrm{wt} \%$ loading of GO was elected as the best conditions. Here, while higher amounts (25 wt \%, entry 4 ) did not bring any benefit at the process, the use of $5 \mathrm{wt} \%$ caused a slight drop in the isolation of $3 \mathrm{aa}(59 \%$, entry 3 ). The choice of the solvent was crucial too. In particular, the addition of water (ca. $20 \% \mathrm{v} / \mathrm{v}$ with $\mathrm{CH}_{3} \mathrm{CN}$ ) was found to be essential for the protocol (entry 9 vs entry 1). ${ }^{[12]}$ The use of water for this class of dearomatizations with alcohols is unprecedented and remarkable.

Proofs of a genuine GO catalysis were gained via dedicated control experiments. In particular, the inefficiency of a background Brønsted acid catalysis was empathized by running the model reaction in the presence of $\mathrm{AcOH}$ (entry 13) and $p$ TSA (Table $\mathrm{S} 1) \cdot{ }^{[13]}$ Additionally, the potential co-catalysis promoted by metal contaminations of $\mathrm{GO}$ (i.e. $\mathrm{Mn}^{2+}$ ) was ruled out via designed experiments with $\mathrm{Mn}(\mathrm{OAc})_{2} \bullet 4 \mathrm{H}_{2} \mathrm{O}$ (entry 14) and cation-trapping EDTA solution (entry 15). The suitability of the protocol towards a gram scale variant was also verified in the presence of $5 \mathrm{mmol}$ of indole $1 \mathrm{a}$ (entry 17$)$. In this case, notable $78 \%$ isolated yield $(1.13$ gr) of 3aa was obtained under model conditions.

Then, we focused on to the scope of the reaction by subjecting several poly-substituted indoles (1b-n) to the GO-assisted condensation with $2 \mathbf{a}$ (Scheme 1).

Scheme 1. Scope of the reaction: the indole.
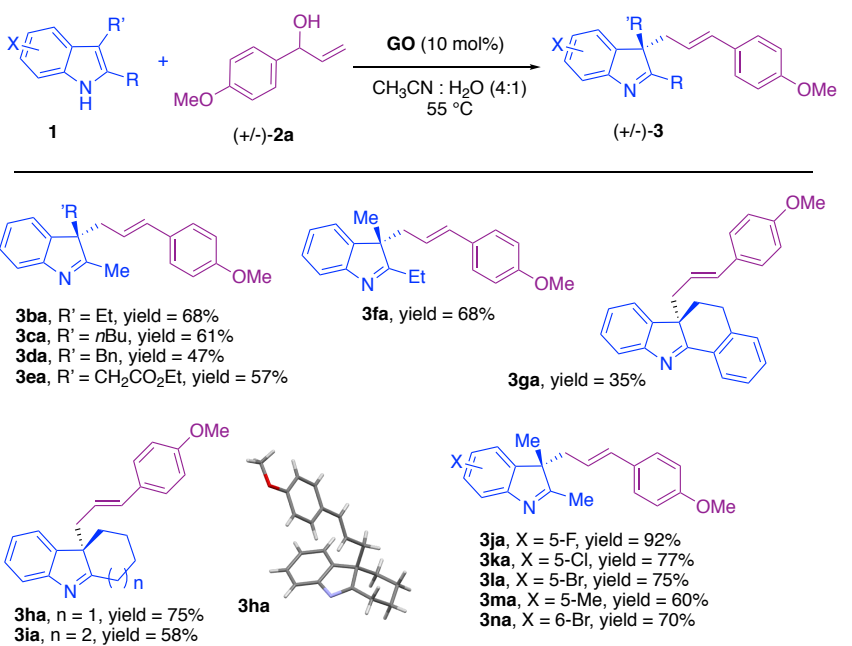
In terms of indole substitutions, different aliphatic as well as aromatic groups could be accommodated at $\mathrm{C}(2)$ and $\mathrm{C}(3)$ positions ( $\mathrm{Et}, n \mathrm{Bu}, \mathrm{Bn}, \mathrm{CH}_{2} \mathrm{CO}_{2} \mathrm{Et}$ ) leaving almost untouched the catalytic performances of the present methodology (yield up to $70 \%$ ). Interestingly, tetrahydrocarbazole $1 \mathrm{~h}$ and 7-membered-ring analogous $1 \mathrm{i}$ worked smoothly in the allylic dearomative process, delivering the corresponding indolenines 3 ha and 3 ia in $75 \%$ and $58 \%$ yield, respectively. ${ }^{[14]}$

Finally, tolerance of the protocol towards electronic perturbation of the benzene ring was assessed with indoles $\mathbf{1 j}$-o. Remarkably, good to excellent yields (up to $92 \%$ ) were recorded regardless the electronic properties of the substituents $(\mathrm{F}, \mathrm{Cl}, \mathrm{Br}$, $\mathrm{Me})$ and their position $(\mathrm{C}(5)$ and $\mathrm{C}(6))$.

The extendibility of the process to different allylic alcohols was then elaborated. A series of secondary $(\mathbf{2 b}-\mathbf{m})$ and tertiary $(\mathbf{2 n - p})$ alcohols was treated with the 2,3-Me $\mathrm{Me}_{2}$-indole $\mathbf{1 a}$ and the corresponding outcomes are collected in the Scheme 2. In all cases, excellent regio- (both indole and alcohol sites) and stereoselectivity was recorded, delivering the desired all-carbon $\mathrm{C}(3)$ quaternary stereogenic center indolenines in up to $84 \%$ yield.

A key feature for the success of the protocol was the presence of electron-donating groups on the aromatic system or electronrich heteroarenes (i.e. thiophene, benzothiophene). Contrarily, unsubstituted arenes or benzenes carrying electron-withdrawing groups did not react even under harsh conditions $\left(120^{\circ} \mathrm{C}, 6 \mathrm{~h}\right)$. In these cases, substantial isomerization of $\mathbf{2} \mathbf{d}$ towards the linear cinnamyl isomer occurred exclusively (vide infra for mechanistic interpretation). Interestingly, also tertiary alcohols $\mathbf{2 n - p}$ did react in a satisfactory manner with $1 \mathrm{a}$ furnishing the corresponding dearomatized heterocycles in excellent yields $(72-84 \%)$ via $S_{N} 2$ type machinery.

Scheme 2. Scope of the reaction: the alcohol.

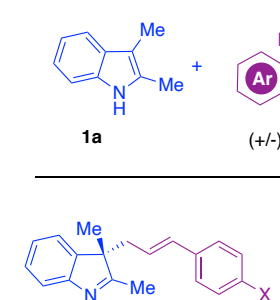

3ab, $X=O B n$, yield $=65 \%$ 3ac, $X=$ OTBDMS, yield $=66 \%$ 3ac, $X=O T B D M S$, yiel
3ad, $X=H$, yield $=N^{b}$ 3ad, $X=\mathrm{H}$, yield $=\mathrm{NR}^{b}$ 3ae, $X=S M e$, yield $=51 \%^{c}$
3af, $X=O\left(\mathrm{CH}_{2}\right)_{5} \mathrm{~N}_{3}$, yield $=76 \%$ 3af, $\mathrm{X}=\mathrm{O}\left(\mathrm{CH}_{2}\right)_{5} \mathrm{~N}_{3}$, yield =

3ak, yield $=63 \%^{a}$
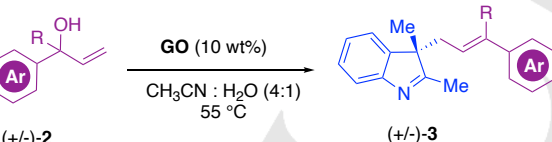

$(+/)-3$

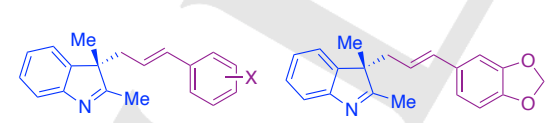

3aj, yield $=66 \%$

3ag, $X=2-\mathrm{OMe}$, yield $=40 \%$ 3ah, $X=3,4-(\mathrm{OMe})_{2}$, yield $=76 \%$ 3ai, $\mathrm{X}=2,4,5-(\mathrm{OMe})_{3}$, yield $=81 \%$
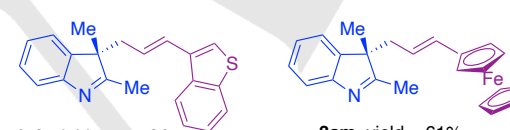

3am, yield $=61 \%$

3al, yield $=53 \%$,

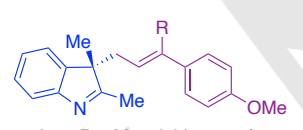

3an, $R=$ Me, yield $=72 \%{ }^{e}$
3ao, $R=n B u$ yield $=80 \%$

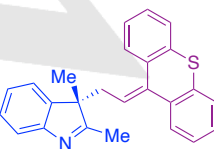

3ap, yield $=84 \%^{d}$

${ }^{a} 10 \%$ of $\mathrm{C}(3) / \mathrm{C}(5)$-diallylated product was formed. ${ }^{b} 120{ }^{\circ} \mathrm{C} .{ }^{c} 70{ }^{\circ} \mathrm{C} .{ }^{d} \mathrm{RT}$. NR $=$ no reaction (branched/linear isomerization of $\mathbf{2 d}$ occurred). ${ }^{c}$ The absolute configuration $E$ of the $\mathrm{C}=\mathrm{C}$ was determined via ${ }^{1} \mathrm{H}-\mathrm{NoE}$ experiments, see $\mathrm{SI}$
Intrigued by these results, we focused on elucidating the mechanism of the process. On the other hand, the use of multifunctionalized nanocarbon promoters/catalysts poses several issues in terms of mechanistic elucidation, since multiple reaction channels can be envisioned.

At first, significative structural modifications of the GO-surface functionalization were observed via XPS analysis (Figures 2a-e). In particular, the treatments of $\mathrm{GO}$ in the reaction media alone (Figure 2b) did not affect significantly the O:C content (pristine GO $0.32: 1$, GO after solvent $0.32: 1$ ). On the contrary, while the treatment of $\mathrm{GO}$ with $1 \mathrm{a}$ decreased slightly the $\mathrm{O}: \mathrm{C}$ ratio $(0.28: 1$, Figure $2 \mathrm{c}$ ), marked $\mathrm{O}: \mathrm{C}$ ratio variations were observed for $\mathrm{GO} / \mathbf{2 a}$ treatment $(0.22: 1$, Figure $2 \mathrm{~d})$ and $\mathrm{GO} / 1 \mathrm{a}+2 \mathrm{a}$ treatment $(0.24: 1$, Figure 2e).

In particular, the chemical structure of $\mathrm{GO}$ changes significantly after heating in the presence of $\mathbf{2 a}$. Here, the epoxy content decreases from $38.3 \%$ to $17.9 \%$ and hydroxyl groups increase from $3.2 \%$ to $9.0 \%$ (See fit of $C 1$ s in Figure 2). This structure modification is compatible with a partial ring-opening of the epoxide units during the reaction course. ${ }^{[15]}$

In addition, a significant drop in carboxylic content of the GO surface, upon treatment via alcohols $2 \mathbf{a}$ or $\mathbf{1 a}+\mathbf{2 a}\left(6 \mathrm{~h}, 55^{\circ} \mathrm{C}\right)$, was observed (Figure 2a vs Figures $2 \mathrm{~d} / \mathrm{e}$ ). In particular, the carboxylic groups decrease from $1.6 \%$ to 0 and $0.6 \%$, respectively. This behavior can be ascribed to the esterification of the carboxylic group present and subsequent decomposition also via decarboxylative events. ${ }^{[9, n, 16]}$

Therefore, we combined all spectroscopic and experimental information with the QM/MM study to elucidate in detail the reaction mechanism that results in a two-step process (see Figure $3 a) .{ }^{[10,17]}$

In step 1 a covalent grafting of the allylic alcohol on the GO surface is observed. The protonation of the epoxide ring on the GO surface leads to an unstable oxonium unit that opens barrierless (Rx) ${ }^{[18]}$ Ring opening of the epoxide groups relieves ring strain and forms a highly stabilized $\alpha$-carbocation, as already observed by Chen et al. ${ }^{[19]}$ Then, the resulting $\alpha$-carbocation undergoes a facile nucleophilic attack by the allylic alcohol (transition state Ts1).

The key role of electron-donating groups on the aromatic system (i.e. 2a) is in agreement with the current mechanistic hypothesis. The comparison of the energetic reaction profiles for the GO grafting of different allylic alcohols showed that a significantly higher barrier is observed for $\mathbf{2 d}$ (unsubstituted benzene) compared to 2a (25.5 vs $10.9 \mathrm{kcal} \mathrm{mol}^{-1}$, Figure S12). The presence of electron-donating groups on the aromatic system contributes to stabilize the positive charges delocalized on the GO surface via strong $\pi-\pi$ interactions between $\mathrm{GO}$ and the aromatic moiety of the alcohol. 

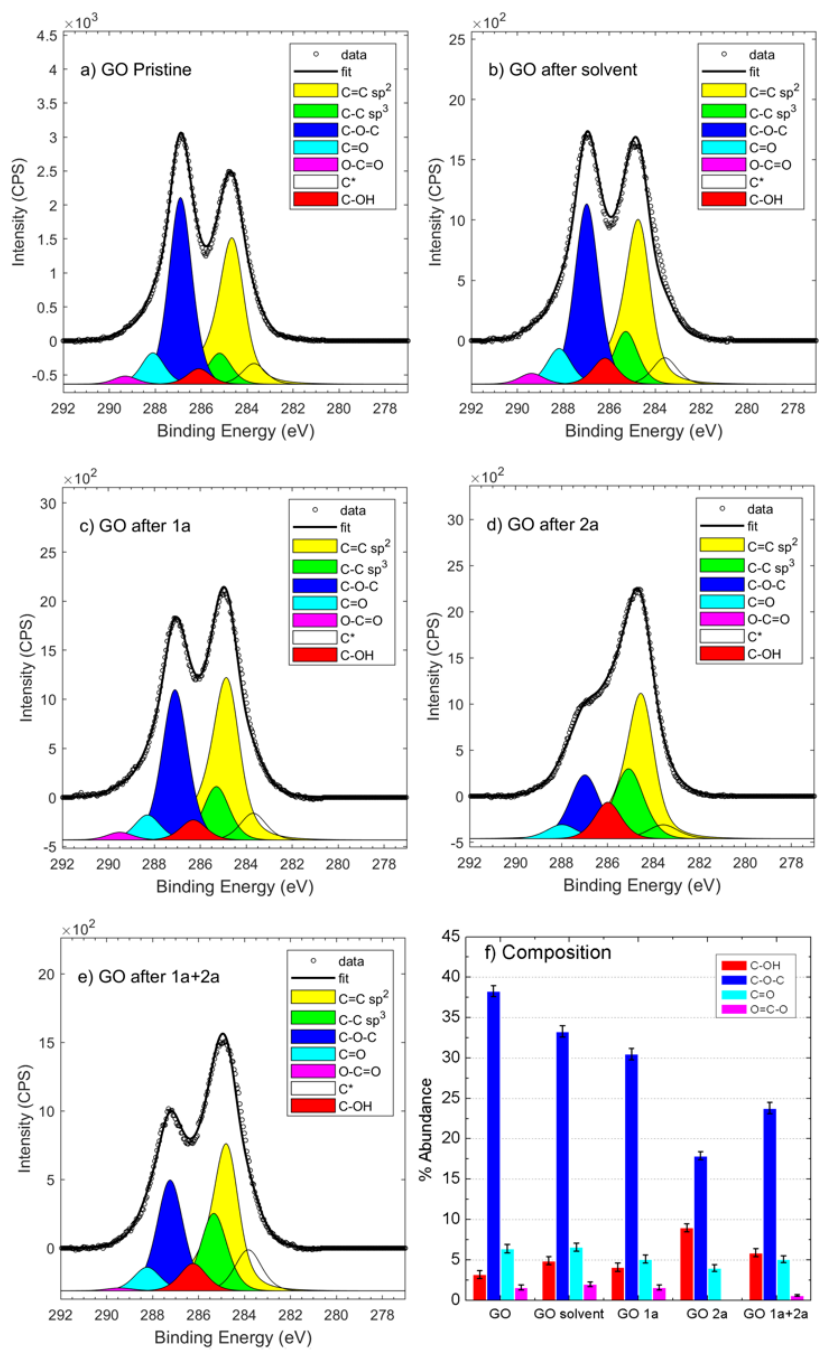

Figure 2. XPS C 1s signal of a) pristine GO; b) GO after $A C N: \mathrm{H}_{2} \mathrm{O} 4: 1$ at $55^{\circ} \mathrm{C}$; c) GO after $1 \mathbf{a}$; d) GO after $\mathbf{2 a}$; e) GO after $1 \mathbf{a}+\mathbf{2 a}$. f) composition of $\mathrm{C}-\mathrm{O}$ groups obtained from fit (a-e). More details on fit procedure in $\mathrm{SI}$.

In step 2, the obtained protonated allyl ether undergoes a $S_{N} 2$ type attack by indole derivatives leading to the observed C(3)allylated dearomatized compound. Step 2 follows a concerted mechanism where either $\mathrm{C}(3)$ or $\mathrm{N}(1)$-atom of the 2,3-Me $\mathrm{Me}_{2}$-indole attacks the allylic position (Ts2), causing an overall reorganization of the $\pi$-system. The $\mathrm{C}(3)$-carbon selectivity emerges clearly from the calculated Ts2 and it is dictated by the GO catalyst.

In particular, the influence of $\mathrm{GO}$ on the regioselective attack by indole is determined by the following factors: i) in the $\mathrm{C}(3)$ dearomatization a stabilizing interaction between the indole $\mathrm{N}(1)$ $\mathrm{H}$ atom and the $\mathrm{GO} \pi$-system is established (Figure $3 \mathrm{~b}$ ). On the contrary, the attack involving the $\mathrm{N}(1)$-position, causes a destabilizing interaction (steric clash) due to steric reasons between the $\mathrm{C}(3)$-methyl group and the graphene sheet (Figure 3c). ${ }^{[2]}$ ii) The above discussed interactions have also important effects on the structure of the indole ring during the $S_{N} 2$ attack: when the reaction is carried out by the $C(3)$, the indole ring shows an ideal geometry for a $S_{N} 2$ attack, since it is orthogonal to the graphene sheet and parallel to the electrophilic site. In contrast, if the attack is carried out by $\mathrm{N}(1)$, a strong deviation from optimal reaction geometry of the indole ring is necessary in order to minimize the steric repulsion between the methyl group and GO. As a consequence, Ts2 C(3) is significantly more stable than Ts2 $\mathrm{N}(1)\left(8.1 \mathrm{kcal} \mathrm{mol}^{-1}\right)$, in perfect agreement with the experimental stereospecificity.

As observed in Step 1, also in Step 2 the presence of electrondonating groups on the aromatic system (better leaving groups) favors the reaction and a higher barrier is observed for the $\mathrm{C}(3)$ allylic alkylation of $\mathbf{2 d}$ compared to $\mathbf{2 a}\left(28.0 \mathrm{vs} 21.4 \mathrm{kcal} \mathrm{mol}^{-1}\right.$, Figure S12).

Interestingly, at the end of the reaction the alcoholic $\mathrm{O}-\mathrm{H}$ group remains grafted on the GO surface $(\mathbf{P d})$ explaining the overall increase of alcoholic moieties versus the oxirane ones spectroscopically observed by XPS analysis before and after the catalysis.

The covalent "grafting" activation model was further supported by means of FT-IR analysis (Figure S2). In particular, the allylic alcohol $2 f$ bearing an azide group was reacted with $\mathrm{GO}$ in $\mathrm{CH}_{3} \mathrm{CN}: \mathrm{H}_{2} \mathrm{O} 4: 1$ at $55^{\circ} \mathrm{C}(6 \mathrm{~h})$ mimicking reaction conditions. The recovered $\mathrm{GO}$ was then analysed via $\mathrm{FT}-\mathrm{IR}$ and compared to $\mathrm{GO}$ stirred with $2 \mathrm{f}\left(\mathrm{MeCN} / \mathrm{H}_{2} \mathrm{O}\right)$ at $0{ }^{\circ} \mathrm{C}$ for $30 \mathrm{~min}$. In the former case, FT-IR displayed the diagnostic $\mathrm{N}_{3}$ stretching at $2100 \mathrm{~cm}^{-1}$ (Figure 4a). Contrarily, a significantly weaker signal was observed in the GO sample treated with $2 \mathrm{f}$ at $0{ }^{\circ} \mathrm{C}$ (Figure S2).

a)

$\mathbf{R x}=[0.0] \quad T s 1=[10.9]$
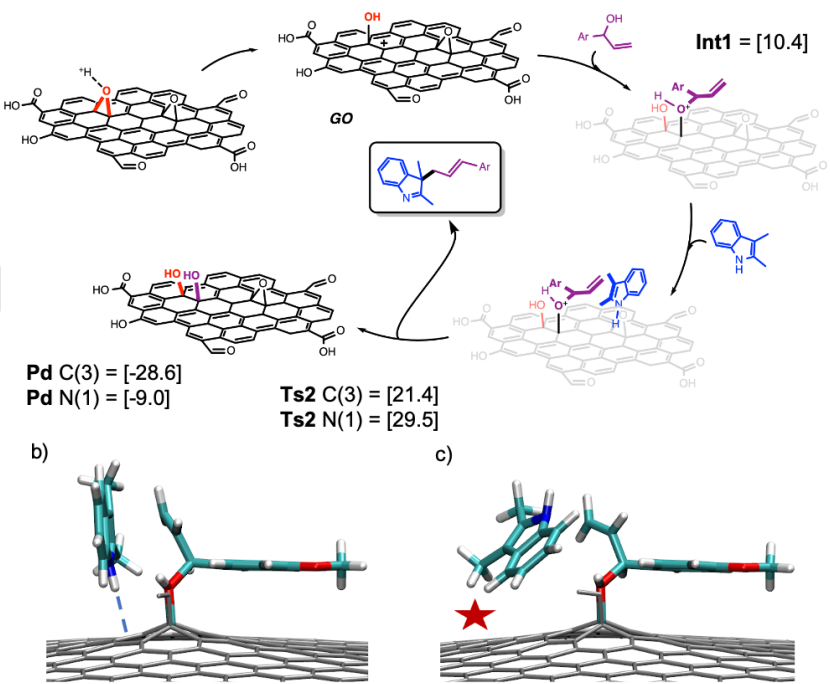

c)

Figure 3. (a) Schematic representation of the reaction mechanism. The energies of the identified critical points in square bracket $\left(\mathrm{kcal} \mathrm{mol}^{-1}\right)$; 3D representation of the identified transition states for the $\mathrm{C}(3)$ (b) and (N1) (c) attack of the indoles.

Similar trend was recorded also via XPS N 1s analysis that confirmed univocally the $\mathrm{N}_{3}$ presence by the characteristic double peak of azides: $404.1 \mathrm{eV}, \mathrm{N}=\mathrm{N}=\mathrm{N}$ and 401.1 for $\mathrm{N}=\mathrm{N}=\mathrm{N}$ (Figure 4c). ${ }^{[21]}$ Contrarily, both pristine $\mathrm{GO}$ and the $\mathrm{GO}$ stirred with $2 \mathrm{ff}$ $\left(\mathrm{MeCN} / \mathrm{H}_{2} \mathrm{O}\right)$ at $0{ }^{\circ} \mathrm{C}$, presented only residual amounts of amino groups in the region 402-399 eV (Figure $4 \mathrm{~b}$ ). 
The remarkable drop in catalytic performance of the recovered GO upon the first run (12\% yield of 3aa in $36 \mathrm{~h}$ ) agrees with the disclosed mechanistic pathway in which both epoxides and carboxylic acids of the GO surface are involved.
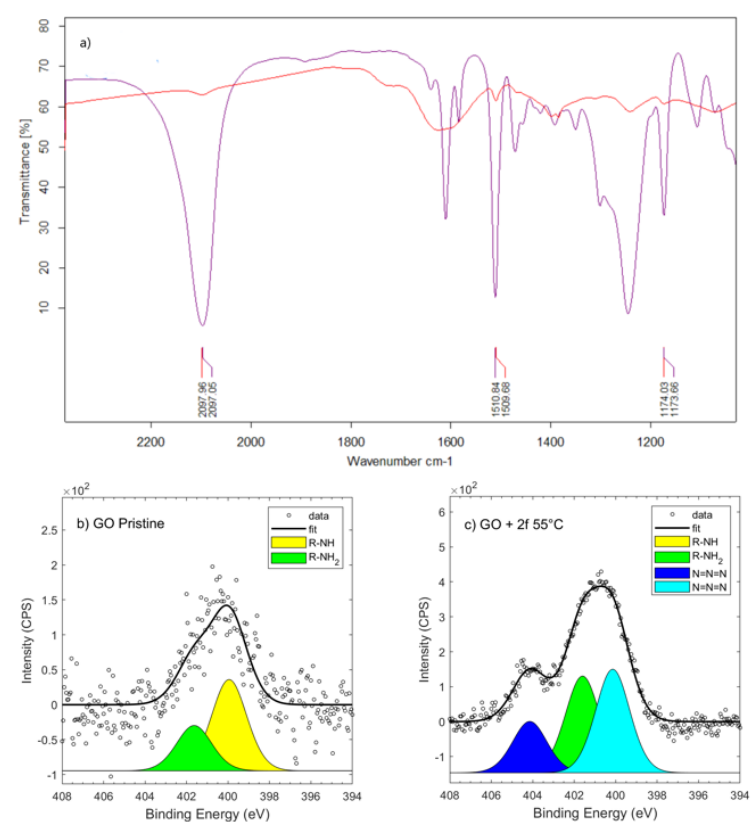

Figure 4. (a) Violet: alcohol 2f. Red: $\mathrm{GO}+\mathbf{2 f}$ after $6 \mathrm{~h}$ in $\mathrm{CH}_{3} \mathrm{CN}: \mathrm{H}_{2} \mathrm{O} 4: 1$ at $55^{\circ} \mathrm{C}$. XPS N 1s signal of pristine $\mathrm{GO}(\mathrm{b})$ and $\mathrm{GO}+2 \mathrm{f}$ after $6 \mathrm{~h}$ in $\mathrm{CH}_{3} \mathrm{CN}: \mathrm{H}_{2} \mathrm{O}$ $4: 1$ at $55^{\circ} \mathrm{C}$ (c).

The evidences for a grafting activation mode exerted by the GO-surface on the alcoholic moiety, prompted us to investigate also the reactivity of propargylic alcohols in the dearomatization process. ${ }^{[2]]}$ In particular, the covalent binding of the carbynol unit on the GO should leave exposed to the approaching indole only the "external" acetylenic carbon (Scheme 3 inset), enabling an unprecedented regioselective allenylative dearomatization of indoles to occur.

Interestingly, we were pleased to verify that the optimal reaction conditions adopted for the allylic alcohols 2 (i.e. $\left.\mathrm{CH}_{3} \mathrm{CN}: \mathrm{H}_{2} \mathrm{O} 4: 1,55{ }^{\circ} \mathrm{C}\right)^{[22]}$ proved competent also in the nucleophilic substitution with secondary and tertiary propargylic derivatives $\mathbf{4 a - e}$. The corresponding allenyl-indolines $\mathbf{5}$ were delivered in good yields (40-94\%) and diastereoisomeric ratio up to $80: 20$ (Scheme 3). It is worth mentioning that this approach represents the first example of indole dearomatization with concomitant site-selective installation of bi-, tri-, and tetrasubstituted allenyl units. ${ }^{[23,24]}$

Additionally, to further explore the synthetic utility of the present methodology, the regeneration of GO was investigated.
Scheme 3. GO-assisted dearomative allenylaton of indoles. ${ }^{a}$

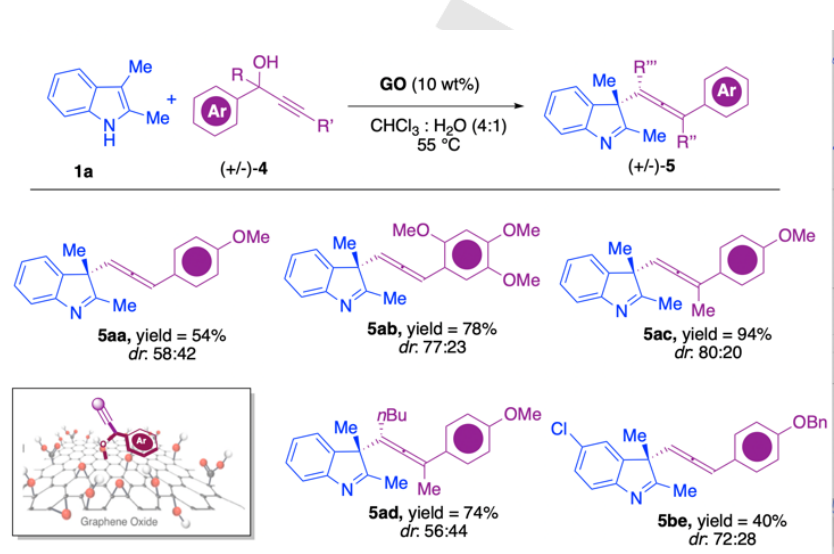

${ }^{a}$ Reaction time: see SI. $d r$ determined on the reaction crude.

Delightly, sonication of the recovered $\mathrm{GO}$ under acidic conditions $(\mathrm{HCl} 1 \mathrm{M}, 1 \mathrm{~h}$, Figure $5 \mathrm{a})$ enabled the simultaneous restoring of the acidity profile and part of the epoxydic content of the pristine GO. As testified by the XPS analysis, the epoxy group increased from $24 \%$ to $30 \%$ upon acid treatment (Figures S7). ${ }^{[19]}$ Once again, the feedback gained from catalysis was in agreement with the structural characterization. As a matter of fact, the regenerated $\mathrm{GO}$ worked similarly to the pristine one when tested in the model reaction (3aa, yield $=63 \%, 36 \mathrm{~h}$, Figure $5 \mathrm{~b}$ ).

a)

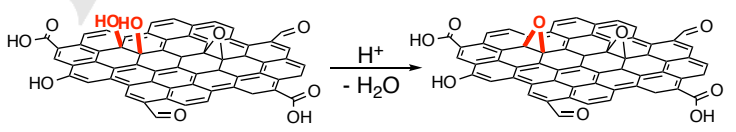

Recovered-GO Regenerated-GO

b)

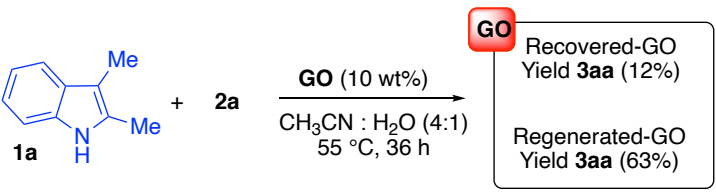

Figure 5. (a) Schematic representation of acidic regeneration GO; (b) Comparing the effectiveness of recovered- and regenerated-GO in the model reaction.

In conclusion, a graphene oxide mediated allylic dearomatization of 2,3-di-substituted indoles with alcohols is presented. The protocol does not require noble-metal catalysis, stoichiometric additives, rigorous anhydrous conditions and comprises facile regeneration of the carbo-nano-material via acidic treatment. From a mechanistic view-point, a synergistic action of the functional groups decorating the graphene surface was discovered providing insight towards a covalent activationmode. Studies towards the exploitation of this efficient GOmediated electrophilic activation of $\pi$-alcohols in other chemical transformations are currently underway in our laboratories

\section{Acknowledgements}


Acknowledgements are made to University of Bologna for financial support. PRIN-2017 project 2017W8KNZW was kindly acknowledged. The research leading to these results has received funding from the European Union's Horizon 2020 research and innovation programme under GrapheneCore2 785219 - Graphene Flagship.

Keywords: Alcohols • Carbocatalysis • Graphene oxide • Dearomatization $\bullet$ Indole

[1] a) S.P. Roche, J.A. Porco, Angew. Chem. Int. Ed. 2011, 50, 4068-4093; b) C.-X. Zhuo, W. Zhang, S.-L. You, Angew. Chem. Int. Ed. 2012, 51, 12662-12686; c) C.-X. Zhuo, C. Zheng, S.-L. You, Acc. Chem. Soc. 2014 47, 2558-2573; d) C. Zheng, S.-L. You, Chem. 2016, 1, 830-857; e) Asymmetric Dearomatization Reactions (Ed. You, S.-L.), Wiley-VCH, 2016; f) W.-T. Wu, L. Zhang, S.L. You, Chem. Soc. Rev. 2016, 45, 1570 $1580 ;$ g) X.-W. Liang, C. Zheng, S.-L. You, Chem. Eur. J. 2016, 22, 11918-11933; h) S. Park, S. Chang, Angew. Chem. Int. Ed. 2017, 56 7720-7738; i) J. An, M. Bandini, CHIMIA 2018, 72, 610-613; j) V Pirovano, Eur. J. Org. Chem. 2018, 1925-1945; j) J. Bariwal, L.G. Voskressensky, E.V. Van der Eycken, Chem. Soc. Rev. 2018, 47, 3831 3848; k) C. Zheng, S.-L. You, Nat. Prod. Rep. 2019, 36, 1589-1605.

[2] For general reviews on the use of allylic/propargylic alcohols in organic synthesis see: a) M. Bandini, M. Tragni, Org. Biomol. Chem., 2009,7, 1501-1507; b) M. Bandini, Angew. Chem. Int. Ed., 2011, 50, 994995; c) M. Bandini; G. Cera; M. Chiarucci, Synthesis, 2012, 44, 504-512; d) B. Sundararaju, M. Achard, C. Bruneau, Chem. Soc. Rev. 2012, 41, 44674483; e) H. Li, C. Mazet, 2016, 49, 1232-1241; f) J. Zhang, J. Liao, Y.-F. Wei, G. Cheng, R. Luo, Mini Rev.Org. Chem. 2018, 15, 476-487; f) H. Qian, D. Huang, Y. Bi, G. Yan, Adv. Synth. Catal. 2019, 361, 3240-3280.

[3] a) M. Kimura, M. Futamata, R. Mukai, Y. Tamaru, J. Am. Chem. Soc. 2005, 127, 4592-4593; b) B. M. Trost, J. Quancard, J. Am. Chem. Soc. 2006, 128, 6314-6315; c) X. Zhang, Z.-P. Yang, C. Liu, S.-L. You, Chem. Sci. 2013, 4, 3239-3243; d) X. Zhang, L. Han, S.-L. You, Chem. Sci. 2014 5, 1059-1063; e) N. Kumar, A. Maity, V.P. Gavit, A. Bisai, Chem. Commun. 2018, 54, 9083-9086.

[4] a) H. Zhang, R.-B. Hu, N. Liu, S.-X. Li, S.-D. Yang, Org. Lett. 2016, 18, 28-31; b) S. Gao, Z. Wu, X. Fang, A. Lin, H. Yao, Org. Lett. 2016, 18, 3906-3909.

[5] For some representative very recent examples see: a) M. Zhu, C. Zheng, X. Zhang, S.-L. You, J. Am. Chem. Soc. 2019, 141, 2636-2644; b) Y.-Z. Cheng, Q.-R. Zhao, Q.-R. Zhao, X. Zhang, S.-L. You, Angew. Chem. Int Ed. 2019, 58, 18069-18074; c) J. Wu, Y. Dou, R. Guillot, C. Kouklovsky, G. Vincent, J. Am. Chem. Soc. 2019, 141, 2832-2837; d) G.-J. Mei, X. Tang, Y. Tasdan, Y. Lu, Angew. Chem. Int. Ed. 2020, 59, 648-652.

[6] General reviews on carbocatalysis: a) D. R. Dreyer, C. W. Bielawski, Chem. Sci. 2011, 2, 1233-1240; b); C.K. Chua, M. Pumera, Chem. Eur J. 2015, 21, 12550-12562; c) D. S. Su, G. Wen, S. Wu, F. Peng, R. Schløgl, Angew. Chem. Int. Ed. 2017, 56, 936-964; d) X. Duan, H. Sun, S. Wang, Acc. Chem. Res. 2018, 51, 678-687; e) P. Veerakumar, P. Thanasekaran, T. Subburj, K.-C. Lin, C, 2018, 4, 54; f) M. Antonietti, N. Lopez-Salas, A. Primo, Adv. Mat. 2019, 31, 1805719; g) C. Campisciano, M. Gruttadauria, F. Giacalone, Chem.Cat.Chem. 2019, 11, 90-113.

[7] A selection of comprehensive articles regarding the use of $\mathrm{GO}$ in organic synthesis: a) D. R. Dreyer, S. Park, C. W. Bielawski, R. S. Ruoff, Chem. Soc. Rev. 2010, 39, 228-240; b) J. Pyun, Angew. Chem. Int. Ed, 2011, 50, 46-48; c) D.R. Dreyer, A.D. Todd, C.W. Bielawski, Chem. Soc. Rev. 2014, 43, 5288-5301; d) S. Navalon, A. Dhakshinamoorthy, M. Alvaro, H. Garcia, Chem. Rev. 2014, 114, 6179-6212; e) D. Haag, H.H. Kung, Top. Catal. 2014, 57, 762-773; f) S. Gupta, R. Banu, C Ameta, R. Ameta, P. B. Punjabi, Top. Curr. Chem. 2019, 377, 13.

[8] S. Presolski, M. Pumera, Angew. Chem. Int. Ed. 2018, 57, 16713-16715.

[9] For representative examples see a) D.R. Dreyer, H.-P. Jia, and C.W. Bielawski, Angew. Chem. Int. Ed. 2010, 49, 6813-6816; b) A. Vijay
Kumar, K. Rama Rao, Tetrahedron Lett. 2011, 52, 5188-5191; c) H.-P. Jia, D.R. Dreyer C.W. Bielawski, Adv. Synth. Catal. 2011, 353, 528-532; d) D.R. Dreyer, H.-P. Jia, A.D. Todd, J. Geng, C.W. Bielawski, Org Biomol. Chem. 2011, 9, 7292-7295; e) H.-P. Jia, D.R. Dreyer, C.W Bielawski, Tetrahedron 2011, 67, 4431-4434; b) D.R. Dreyer, C.W. Bielawski, Adv. Funct. Mat. 2012, 22, 3247-3253; f) M.R. Acocella, M. Mauro, G. Guerra, ChemSusChem 2014, 7, 3279; g) F. Hu, M. Patel, F. Luo, C. Flach, R. Mendelsohn, E. Garfunkel, H. He, M. Szostak, J. Am. Chem. Soc. 2015, 137, 14473-14480; h) C. Su, R. Tandiana, J. Balapanuru, W. Tang, K. Pareek, C.T. Nai, T. Hayashi, K.P. Loh, J. Am. Chem. Soc. 2015, 137, 685-690; i) Y. Gao, P. Tang, H. Zhou, W. Zhang, H. Yang, N. Yan, G. Hu, D. Mei, J. Wang, D. Ma, Angew. Chem. Int. Ed., 2016, 55, 3124-3128; j) M.R. Acocella, L. D'Urso, M. Maggio, and G. Guerra, ChemCatChem 2016, 8, 1915; k) Y.R. Girish, S. Pandit, S Pandit, M. De, Chem. Asian J. 2017, 12, 2393-2398; I) H. Wu, C. Su, R. Tandiana, C. Liu, C. Qiu, Y. Bao, J. Wu, Y. Xu, J. Lu, D. Fan, K.P. Loh, Angew. Chem. Int. Ed. 2018, 57, 10848-10853; m) L. Favaretto, J. An, M. Sambo, A. De Nisi, C. Bettini, M. Melucci, A. Kovtun, A. Liscio, V. Palermo, A. Bottoni, F. Zerbetto, M. Calvaresi, M. Bandini, Org. Lett. 2018, 20, 3705-3792; n) G. Meng, M. Patel, F. Luo, Q. Li, C. Flach, R. Mendelsohn, E. Garfunkel, H. He, M. Szostak, Chem. Commun. 2019, 55, 5379-5382; o) M. Karthik, P. Suresh, ACS Sust.Chem.Eng. 2019, 7, 9028-9034; p) H. Wu, C. Qu, Z. Zhang, B. Zhang, S. Zhang, Y. Xu, H. Zhou, C. Su, K.P. Loh, DOI:10.1002/adsc.201901224

[10] a) G. Cera, M. Chiarucci, A. Mazzanti, M. Mancinelli, M. Bandini, Org. Lett. 2012, 14, 1350-1353; b) C. Romano, M. Jia, M. Monari, E. Manoni, M. Bandini, Angew. Chem. Int. Ed. 2014, 53, 13854-13857; c) L. Rocchigiani, M. Jia, M. Bandini, A. Macchioni, ACS Catal. 2015, 5, 39113915; d) R. Ocello, A. De Nisi, M. Jia, Q.-Q. Yang, P. Giacinto, A. Bottoni, G.P. Miscione, M. Bandini, Chem. Eur. J. 2015, 21, 18445-18453; e) J. An, A. Parodi, M. Monari, M. Castiñeira Reis, C. Silva Lopez, M. Bandini, Chem. Eur. J. 2017, 23, 2442-2449; f) P. Giacinto, A. Bottoni, A. Garelli, G.P. Miscione, M. Bandini, Chem CatChem. 2018, 10, 2442-2449; g) J. An, L. Lombardi, S. Grilli, M. Bandini, Org. Lett. 2018, 20, 7380-7383; h) A. Cerveri, O. Nieto Faza, C. Silva Lopez, S. Grilli, M. Monari, M. Bandini, J. Org. Chem. 2019, 84, 6347-6355.

[11] In addition of 3aa, $\mathrm{C}(3)$ and $\mathrm{C}(5)$-diallylated compound was observed in the reaction crude (ca. 10\%).

[12] Although the role of water is not fully understood at the present, the following aspects could be highlighted: 1) improving the solubilization of $\mathrm{GO}$ in the reaction media; 2) acting as proton shuttle during the whole reaction process; 3 ) increasing acidic sited of the $\mathrm{GO}$ via partial interconversion of tertiary alcohol into highly enolizable ketones: $A$. Dimiev, D.V. Kosynkin, L.B. Alemany, P. Chaguine, J.M. Tour, J. Am. Chem. Soc. 2012, 134, 2815-2822.

[13] See SI for a complete list of conditions screening.

[14] The use of skatole led to the formation of $\mathrm{C}(2)$-allylated compound, exclusively.

[15] A. Kovtun, D. Jones, S. Dell'Elce, A. Liscio, V. Palermo, Carbon 2019, 143, 268-275.

[16] D.R. Dreyer, S. Murali, Y. Zhu, R.S. Ruoff, and C.W. Bielawski, J. Mat Chem. 2011, 21, 3443-3447.

[17] a) P. Giacinto, A. Bottoni, M. Calvaresi, F. Zerbetto, F. J. Phys. Chem. C 2014, 118, 5032-5040; b) K. Spyrou, M. Calvaresi, E. K. Diamanti, T. Tsoufis, D. Gournis, P. Rudolf, F. Zerbetto, Adv. Funct. Mater. 2015, 25, 263-269; c) P. Giacinto, F. Zerbetto, A. Bottoni, M. Calvaresi, J. Chem. Theory Comput. 2016, 12, 4082-4092; d) T. D. Marforio, A. Bottoni, P. Giacinto, F. Zerbetto, M. Calvaresi, J. Phys. Chem. C 2017, 121, 2767427682.

[18] R. Ramírez-Jiménez, M. Franco, E. Rodrigo, R. Sainz, R. Ferrito, A.M. Lamsabhi, J.L. Aceña, M. Belén Cid, J. Mater. Chem. A. 2018, 6, 1263712646.

[19] V. D. Ebajo Jr., C. R. L. Santos, G. V. Alea, Y. A. Lin, C.-H. Chen, Scient. Reports 2019, 9, 15579.

[20] As a partial support, when 1,2,3-trimethyl-indole was utilized in the process, the reaction was completely inhibited. 
[21] R.A. Zangmeister, T. A. Morris, M.J. Tarlov, Langmuir 2013, 29, 86198628.

[22] The use of stoichiometric amounts of pTSA or AcOH in the reaction of 1a and $\mathbf{4 a}$ resulted in a complete polymerization of the starting materials or delivered $\mathbf{5 a a}$ only in traces, respectively.

[23] For some representative examples of condensations of indoles and propargylic alcohols see: a) J. S. Yadav, B. V. Subba Reddy, K. V. Raghavendra Rao, G. G. K. S. Narayana Kumar, Tetrahedron Lett., 2007, 48, 5573-5576; b) H. Matsuzawa, K. Kanao, Y. Miyake, Y. Nishibayashi, Org. Lett. 2007, 9, 5561-5564; c) R. Sanz, D. Miguel, A. Martínez, M.
Gohain, P. García-García, M.A. Fernández-Rodríguez, E. Álvarez, F. Rodríguez, Eur. J. Org. Chem. 2010, 7027-7039; c) X. Zhang, W. Teng T. Sally, P. Wai, H. Chan, J. Org. Chem., 2010, 75, 6290-6293; d) L. Zhang, Y. Zhu, G. Yin, P. Lu, Y. Wang, J. Org. Chem. 2012, 77, 95109520; e) S. Gujarathi, H. P. Hendrickson, G. Zheng, Tetrahedron Lett., 2013, 54, 3550-3553; f) K. Selvaraj, S. Debnath, K. C. Kumura Swamy, Org. Lett. 2019, 21, 5447-5451;

[24] R. Roy, S. Saha, RSC Adv. 2018, 8, 31129-31193. 


\section{COMMUNICATION}

Graft-on. The covalent "catalysis" exerted by graphene oxide on the site-selective dearomatization of indoles with allylic/propargylic alcohols is presented under metal-, additive- and anhydrous-free conditions (see scheme).

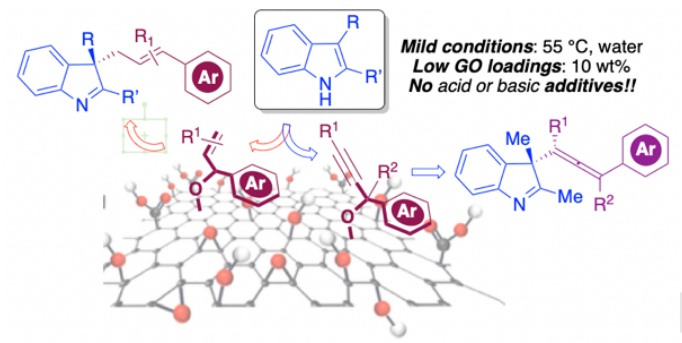

L. Lombardi, D. Bellini, A. Bottoni, M. Calvaresi, M. Monari, A.

Kovtun, V. Palermo, M. Melucci, M. Bandini*

Page No. - Page No.

Allylic and Allenylic

Dearomatization of Indoles promoted by Graphene Oxide via Covalent Grafting

Activation Mode 